\title{
Pulmonary artery banding in congenital heart disease associated with pulmonary hypertension
}

\author{
J.M. REID, R. S. B A R CLAY,E. N. COLEMAN, J.G. STEVENSON, \\ T. M. WELSH, AND N. MCSWAN
}

From the Cardio-thoracic Unit, Mearnskirk Hospital, and the Department of Cardiology and the University Department of Child Health, Royal Hospital for Sick Children, Glasgow

\begin{abstract}
A report is presented of pulmonary artery banding in 45 children with congenital heart disease associated with severe pulmonary hypertension. The majority were in uncontrollable heart failure and were in the age group 3 to 18 months. Nine older children not in heart failure were operated on because of serious pulmonary hypertension associated with malformations considered unsuitable for complete repair (truncus arteriosus, single ventricle). The mortality in those with uncomplicated ventricular septal defect was low $(5.5 \%)$, but was much higher in those with accompanying lesions or more complex abnormalities $(63 \%)$. All have been under supervision since operation and most have improved with diminution in cardiac size and recession of pulmonary congestion. Two have been recatheterized and both have undergone successful closure of their ventricular septal defect. It is our intention to reinvestigate many of the others three to four years after banding to assess the size of the defect prior to further surgery.
\end{abstract}

Muller and Dammann (1952) were the first to recommend constricting the pulmonary artery as a temporizing procedure in infants with large ventricular septal defects, pulmonary hypertension, and intractable cardiac failure. Subsequently, they broadened the indications to embrace older children developing progressive pulmonary vascular disease and also those with uncorrectable malformations such as single ventricle. Since then many communications on this subject have been published (Dammann, McEachen, Thompson, Smith, and Muller, 1961 ; Craig and Sirak, 1963 ; Ochsner, Cooley, McNamara, and Kline, 1962 ; Goldblatt, Bernhard, Nadas, and Gross, 1965 ; Thompson, Muller, and Dammann, 1958 ; and Morrow and Braunwald, 1961), but relatively few have appeared in British journals (Grainger, Nagle, Pawidapha, Robertson, Taylor, Thornton, Verel, and Zachary, 1967).

We wish to record our experience with pulmonary artery banding in a group of 45 infants and children encountered from January 1962 to July 1967, a period of approximately five and a half years.

\section{MATERIAL}

Thirty-four of the patients in our series were aged between 3 and 12 months, three between 13 and 24 months, and the eldest of the remaining eight was 10 years. The majority were infants and very young children who had congestive cardiac failure accompanying pulmonary hypertension at or close to systemic level not fully responsive to digitalization and intensive diuretic therapy, and who were not thriving and unlikely to survive early childhood. By contrast the older children were not acutely ill but had exertional dyspnoea, radiographic evidence of cardiac enlargement, and pulmonary hypertension ranging from $75 / 0$ to $160 / 20 \mathrm{~mm}$. Hg. The reason for not carrying out a complete repair of their cardiac lesions in preference to pulmonary artery banding will be discussed later. Table I presents details of a diagnostic classification related to death at operation and survival. The diagnosis was made by cardiac catheterization and angiocardiography and was confirmed at either operation or necropsy.

\section{RESULTS}

GROUP 1 These patients had a ventricular septal defect with pulmonary hypertension and no other abnormality. The group comprised 18 of our 45 patients, and their ages ranged from 3 months to 9 years. With the exception of three children aged respectively 3,8 , and 9 years, the remainder were 17 months or younger and were admitted with severe congestive cardiac failure and failure to thrive. As intensive medical management failed to alleviate their symptoms, full cardiac investigation was undertaken. 
T A B L E I

DIAGNOSIS IN 45 PATIENTS WHO UNDERWENT PULMONARY ARTERY BANDING FOR SEVERE PULMONARY HYPERTENSION

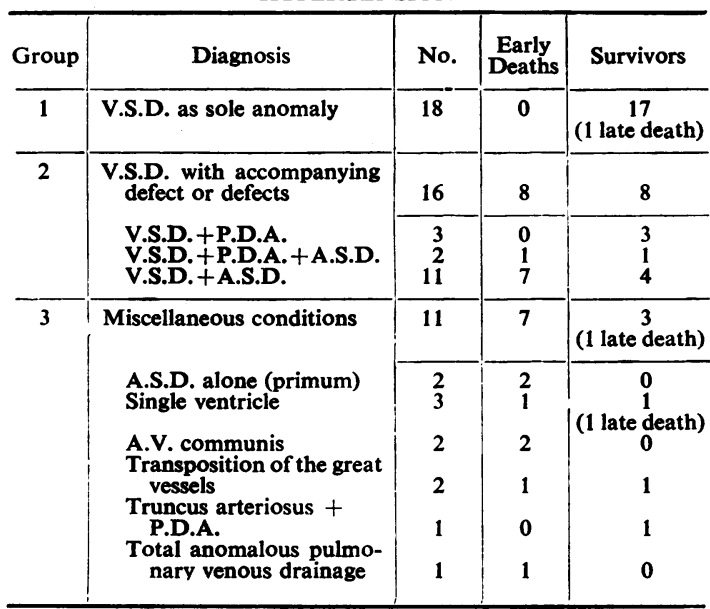

All had clinical and radiographic evidence of cardiomegaly, the cardio-thoracic ratio used as a yardstick measuring from 60 to $70 \%$. Right ventricular hypertrophy was present in the electrocardiogram in eight, left ventricular hypertrophy in two, biventricular hypertrophy in four, and in the remaining four no abnormality was noted. Cardiac catheterization and cineangiocardiography confirmed the presence of a large ventricular septal defect in all, the pulmonary: systemic ratio varying from $1 \cdot 5: 1$ to $4: 1$. The pulmonary artery pressure ranged from $40 / 20$ to $88 / 50$ $\mathrm{mm}$. $\mathrm{Hg}$, the lower pressures in this range merely reflecting the lower systemic arterial pressure of the younger patients. The pulmonary vascular resistance of these 15 varied from 3 to 10 units.

The three older children presented a somewhat different clinical problem. Although not in cardiac failure, they also had serious pulmonary hypertension approximating to systemic level. The highest pressure recorded was $160 / 80 \mathrm{~mm}$. $\mathrm{Hg}$ in a child of 9 years. The pulmonary vascular resistance in these three measured 7, 8, and 27 units respectively. Experience has taught us that closure of a ventricular septal defect in the face of such a pressure courts a very formidable mortality. The lesser procedure of pulmonary artery banding was thus adopted with the object of trying to prevent further pulmonary vascular disease occurring in these children. It is our intention to reinvestigate them three to four years after banding to reassess the feasibility of a repair of their defect.

The operation of pulmonary artery banding is standard and has been adequately reported (Morrow and Braunwald, 1961). We did not differ in our operative technique, the banding being accomplished by means of floss silk. In some patients early in the series an attempt to control the degree of banding was based on pressure evaluation in both pulmonary artery and right ventricle. Figures 1, 2, and 3 depict such a record obtained at operation. There is considerable doubt as to the validity of pressures taken on the operating table, particularly in these very ill infants, and we now no longer rely on this measurement. Our present policy is to reduce the calibre of the pulmonary artery by $50 \%$.

One death occurred in these 18 patients. This was an infant aged 3 months who, in addition to a large ventricular septal defect, had serious pulmonary con-

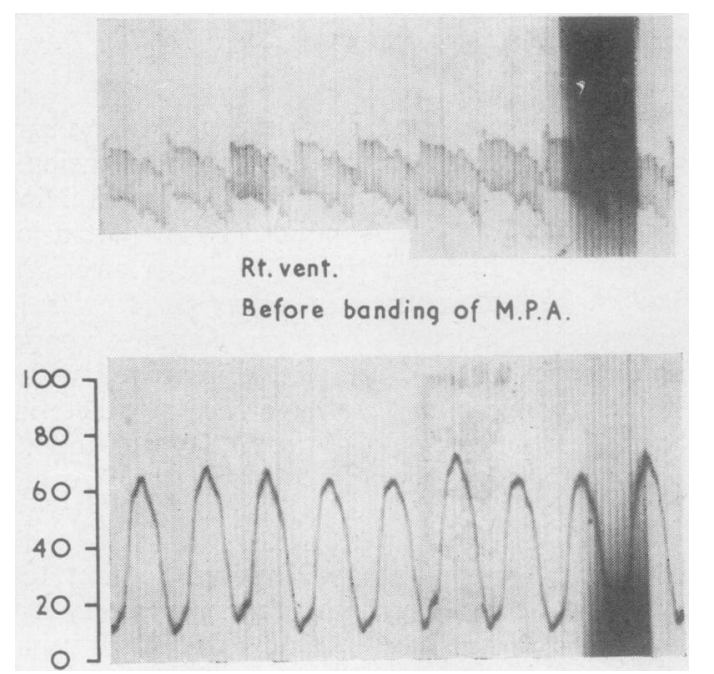

FIG. 1. Tracing from right ventricle obtained at operation prior to banding of pulmonary artery.

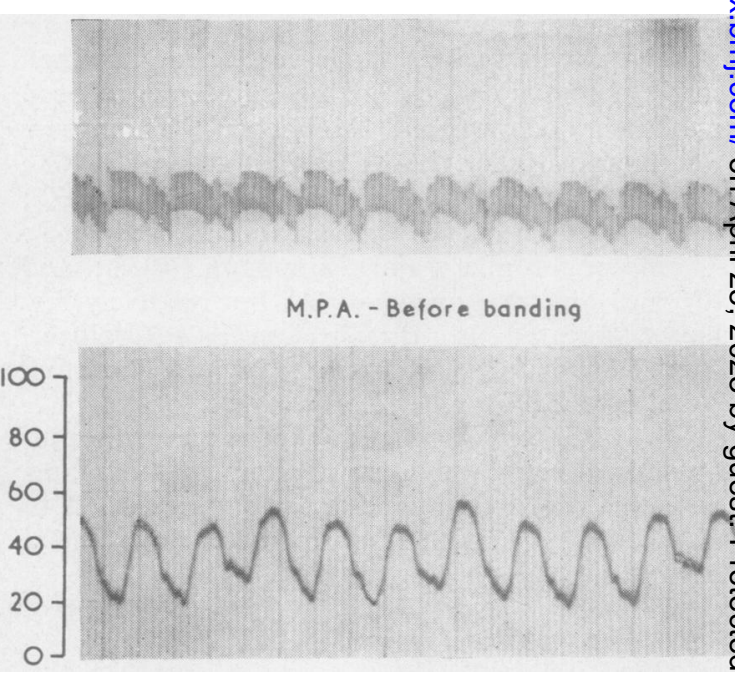

FIG. 2. Pressure in pulmonary artery obtained at operation prior to banding. 

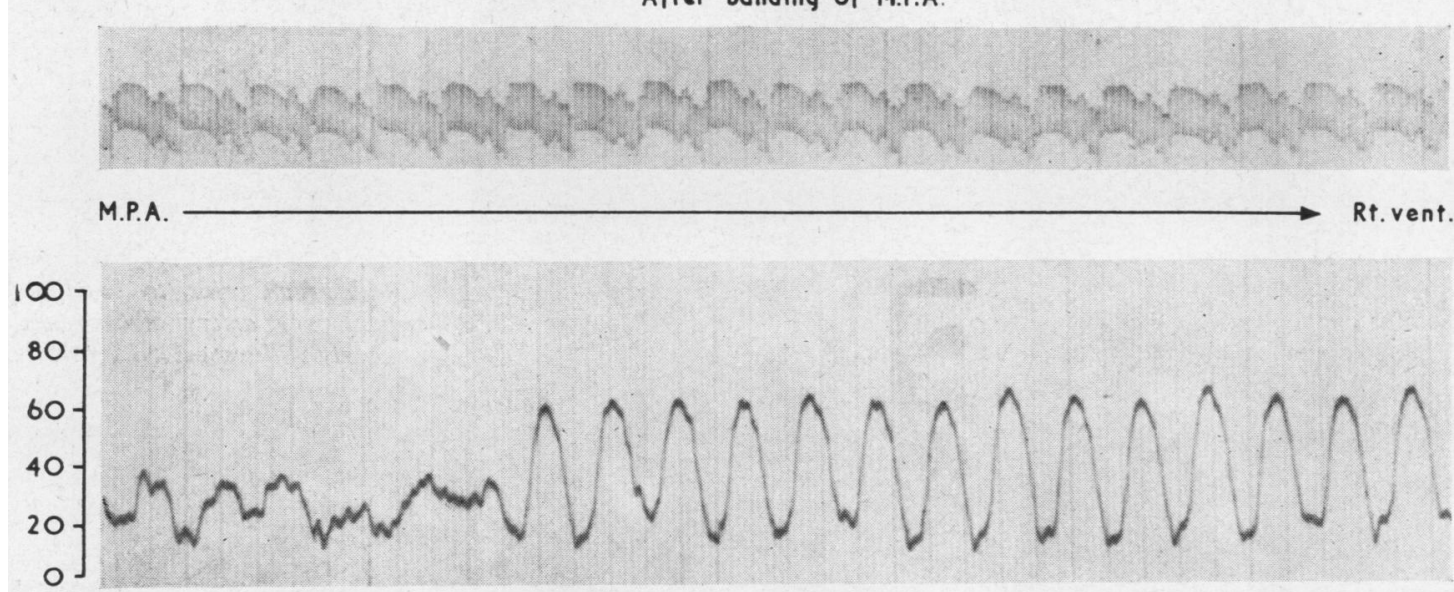

FIG. 3. Record obtained at operation after pulmonary artery banding. This is a withdrawal tracing from pulmonary artery to right ventricle and shows the degree of constriction produced by banding.

gestion. The pulmonary pressure was $70 / 30 \mathrm{~mm}$. $\mathrm{Hg}$, the pulmonary:systemic ratio $3 \cdot 5: 1$, and the P.V.R. 5 units. The infant was prone to severe recurrent respiratory infections. After some initial improvement, she died 10 weeks after operation. Post-mortem examination revealed diffuse bilateral bronchopneumonia and a very large defect in the ventricular septum. The pulmonary artery banding appeared satisfactory.

The remaining 17 patients have been followed since operation for periods ranging from four months to three years. Cardiac catheterization has been repeated in two who underwent banding three years previously, and the relevant pressures are shown in Table II.

T A B L E I I

CATHETERIZATION DATA BEFORE AND AFTER BANDING OF PULMONARY ARTERY IN TWO PATIENTS

\begin{tabular}{c|c|c|c|c|c}
\hline \multirow{2}{*}{ Case } & \multicolumn{2}{|c|}{$\begin{array}{c}\text { Before Banding } \\
\text { (mm. Hg) }\end{array}$} & \multicolumn{2}{|c}{$\begin{array}{c}\text { 3 Years after Banding } \\
\text { (mm. Hg) }\end{array}$} \\
\cline { 2 - 5 } \cline { 5 - 6 } & P.A. & R. Ventricle & P.A. & R. Ventricle \\
\hline 1 & $60 / 35$ & $62 / 0$ & $88 / 27$ & $110 / 0$ \\
2 & $88 / 50$ & $103 / 0$ & $50 / 20$ & $118 / 0$ \\
\hline
\end{tabular}

Both patients have been reoperated on successfully at the age of 4 years, three years after pulmonary artery banding. The defect which in each measured $1 \mathrm{~cm}$. in diameter was repaired easily by direct suture, and the segment of constricted pulmonary artery was reconstructed to restore it to a normal calibre. The radiographic changes following banding and final repair of the defect are illustrated in Figures 4, 5, and 6.

GROUP 2 In this category are included those patients who, in addition to a ventricular septal defect with pulmonary hypertension, had either a persistent ductus arteriosus (3), an atrial septal defect (11), or both (2).
This group comprised 16 patients, of whom 14 were infants and two were aged 3 and 4 years respectively. All were in refractory cardiac failure and had considerable cardiac enlargement. The electrocardiogram in eight showed right ventricular hypertrophy and biventricular hypertrophy in the remainder. The pulmonary: systemic ratio ranged from $2: 1$ to $8: 1$, which represents a torrential pulmonary blood flow. In most the pulmonary artery pressure equalled the systemic and the P.V.R. ranged from 4 to 20 units. There were eight deaths, in two of whom post-mortem examination disclosed additional valve abnormalities (a biscuspid aortic valve and tricuspid incompetence). The P.V.R. was calculated in only four of those who died, and measured 4, 6, 7, and 20 units respectively.

The survivors have all shown substantial improvement since operation, as evidenced by the clinical status, regression of the signs of cardiac failure, and diminution in both pulmonary vascularity and heart size. In this context the most drastic reduction in cardiomegaly was noted in an infant of 4 months, in whom the cardio-thoracic ratio decreased from $70 \%$ to $58 \%$. One patient in this group, in whom the diagnosis was ventricular septal defect and persistent ductus arteriosus, has undergone a repeat cardiac catheterization, followed by a second operation. At the initial operation banding of the pulmonary artery alone was carried out, the ductus being overlooked. At the second catheterization the pulmonary artery pressure had dropped from $55 / 20$ to $30 / 10 \mathrm{~mm}$. $\mathrm{Hg}$. with only a slight rise in right ventricular pressure from $55 / 0$ to $60 / 0 \mathrm{~mm}$. $\mathrm{Hg}$. Three years after banding of the pulmonary artery a repeat operation was performed with the intention of closing the ventricular septal defect and ligating the ductus. After obliterating the ductus, the ventricle was explored to reveal an intact septum, presumably due to spontaneous closure of the defect. 


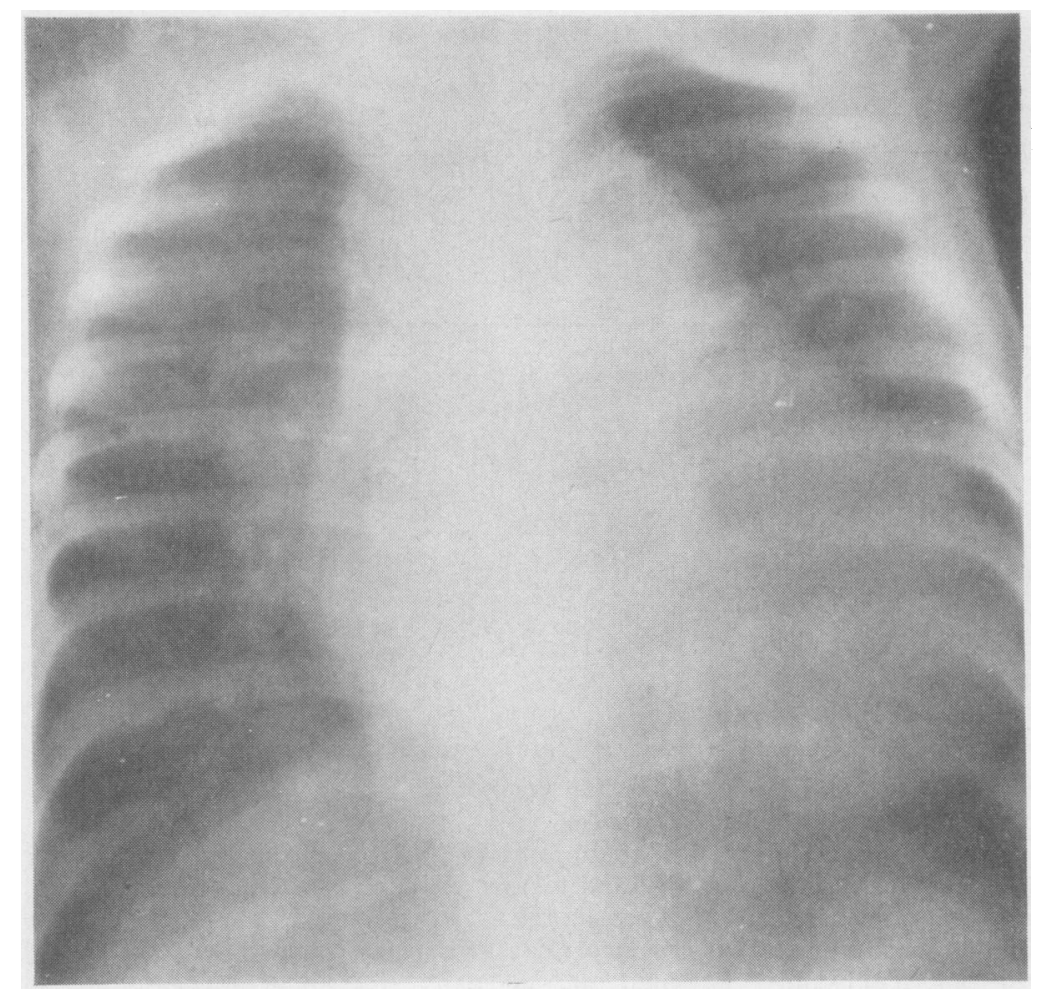

FIG. 4. Case 1, aged 6 months. Radiograph prior to banding $\overline{\phi p}$ pulmonary artery shows cardio megaly with vascular lung fields.

FIG. 5. Case 1, 3 years "after pulmonary artery banding but prior to repeat operation. The pulmonary vascularity is somewhat decreased.

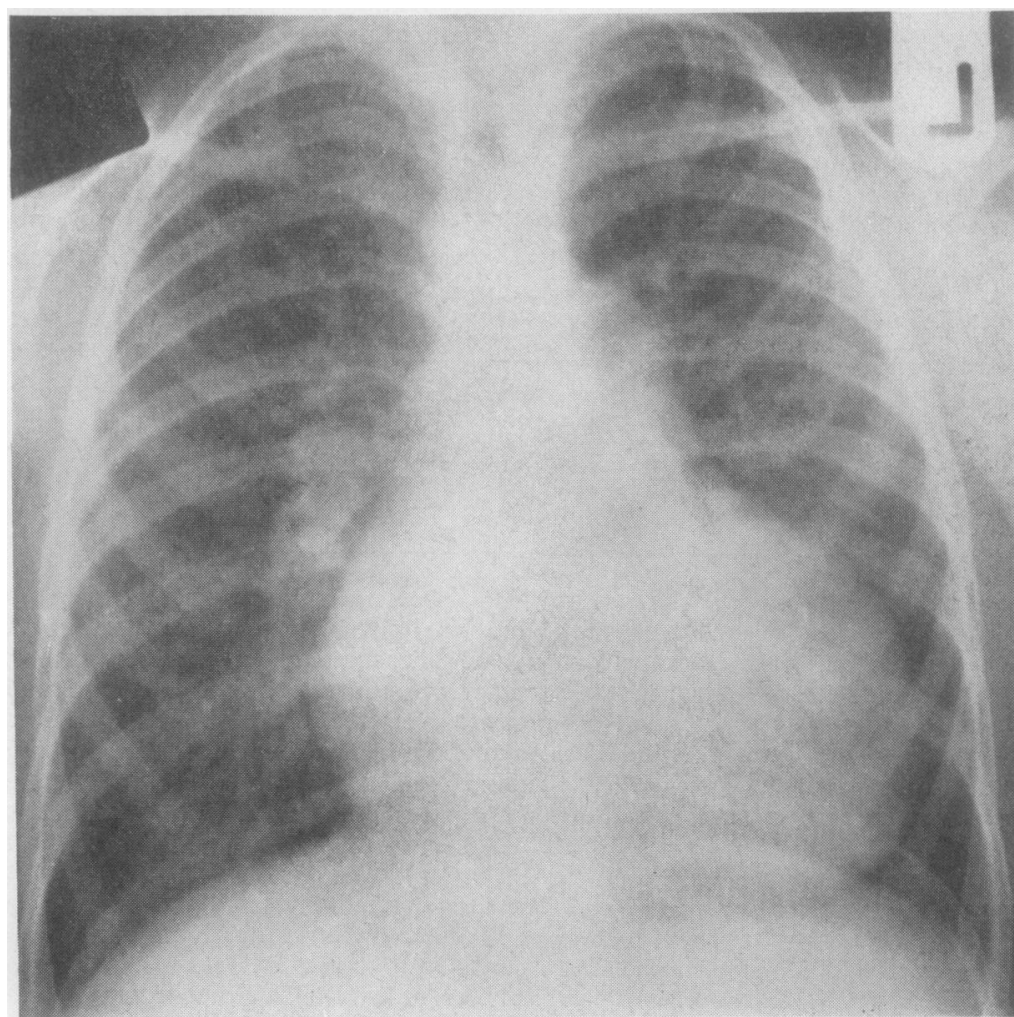




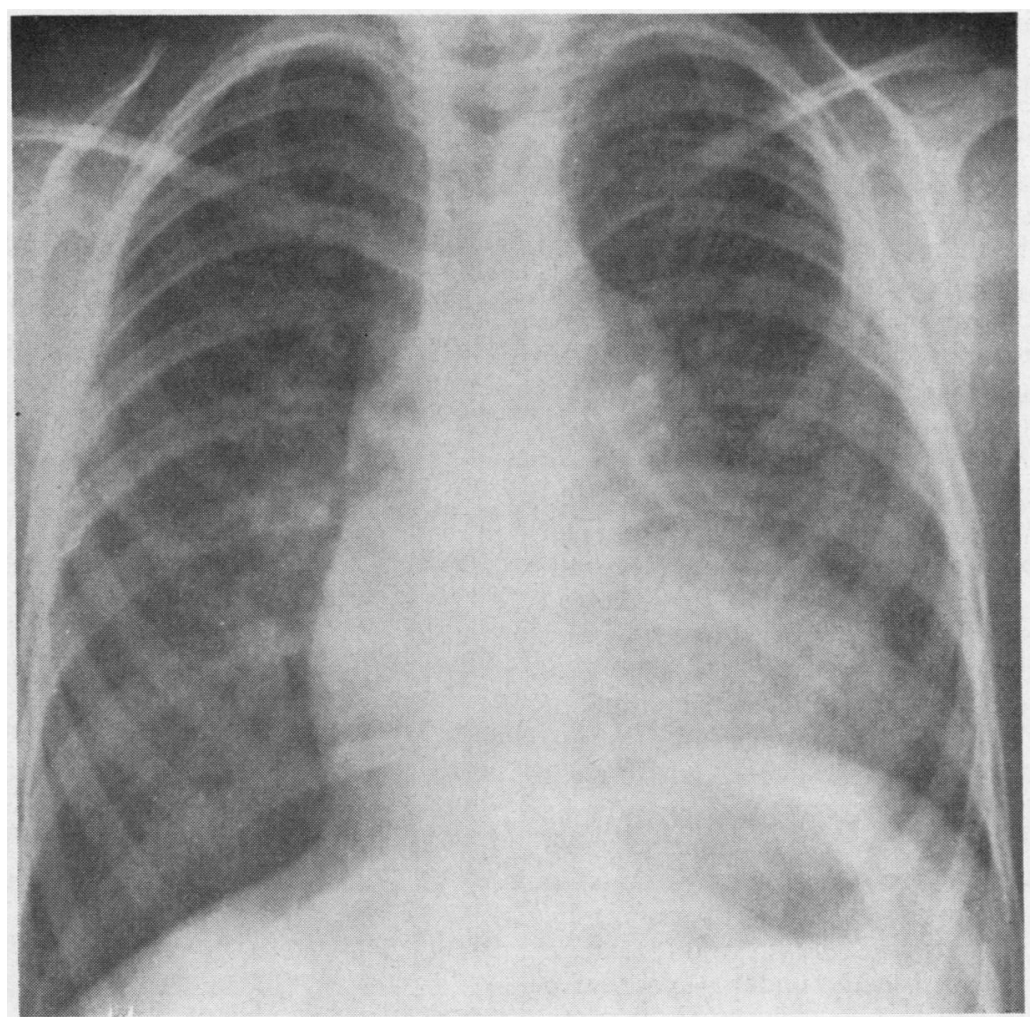

FIG. 6. Case 1. Radiograph six months after repeat operation for successful closure of V.S.D. and removal of pulmonary artery constriction produced at first operation. The heart size is now virtually normal.

GROUP 3 This group comprised 11 patients in whom the diagnosis was for the most part complex and where it was thought that corrective surgery was not feasible. The P.V.R. estimated in only five varied from 4 to 20 units. Three infants with a single ventricle underwent banding of the pulmonary artery in an attempt to reduce the blood flow and thereby halt the inexorable progression of pulmonary vascular disease. Of the two who survived operation, one died three months later during an intercurrent respiratory infection, but permission for necropsy was not obtained. The other is still alive and is slightly improved. Two infants with transposition of the great vessels and gross pulmonary hypertension are included in this group; the one who survived operation is still alive three years later. Common atrio-ventricular canal accounted for a further two, but both died shortly after return from the theatre. One girl aged 10 years with persistent truncus arteriosus and persistent ductus arteriosus and a P.V.R. of 20 units successfully underwent ligation of the ductus and pulmonary artery banding. During the three years since operation she has shown some improvement with lessening in the degree of cyanosis and an increase in exercise tolerance. Lastly, the procedure was performed in three patients who were seriously incapacitated but in whom the diagnosis was not clearly established beforehand. None survived operation. Post-mortem examination in one disclosed total anomalous pulmonary venous drainage with a very small atrial septal defect; in the second there was an atrial septal defect with partial anomalous pulmonary venous drainage; and in the third an ostium primum atrial septal defect was accompanied by corrected transposition of the great vessels and mitral incompetence.

In this group the indications for pulmonary artery banding are less clear-cut. if not suspect. Seven out of 11 died, but these patients were by and large operated on four or five years ago. Since then our pre-operative assessment and investigation have improved immeasurably, and our surgical management has altered. The infant with total anomalous pulmonary venous drainage would now have the small atrial septal defect enlarged as a preliminary procedure, to be followed at a later date by a full corrective operation. Similarly, the two infants with transposition might have benefited from the creation of an artificial atrial septal defect. but neither would have been suitable at any 
stage for a Mustard operation, as the pulmonary artery pressure was at systemic level.

\section{DISCUSSION}

In infants who have large ventricular septal defects, serious pulmonary hypertension, and grave cardiac failure unresponsive to medical treatment, urgent surgical treatment may prove life-saving (Nadas, 1963). In children under 2 years a corrective procedure to close the defect carries a formidable mortality (Thompson et al., 1958). Ochsner et al. (1962) performed a repair of the defect in 31 in this age group, of whom 13 died. They, as with most authors, now recommend a two-stage procedure, namely, banding the pulmonary artery as a preliminary, to be followed several years later when the child is aged 4 years by a repair of the defect.

Friedberg (1966), acknowledging the value of pulmonary artery constriction in infants in uncontrollable failure due to large left-to-right shunts, indicated that total correction may now be feasible as a result of the improvements which have taken place in perfusing small infants in recent years. In support of this is the report by Sloan, Mackenzie, Morris, Stern, and Sigmann (1962) of 56 children mostly under 1 year who were operated on with bypass technique. Of these, 30 had isolated ventricular septal defects, and eight deaths occurred. These infants, however, present exceptional problems both during and after perfusion, and until such gratifying results can be duplicated in many other centres, banding of the pulmonary artery as a preliminary procedure must still fill an important role in the initial management.

Denying these desperately ill infants the benefits of this palliative procedure will result in a fatal outcome in many, in what now can be regarded as a curable abnormality in most. Furthermore, Auld, Johnson, Gibbons, and McGregor (1963), who performed cardiac catheterization at spaced intervals in infants with large left-to-right intracardiac shunts, demonstrated a progressive elevation of pulmonary vascular resistance. Thus patients with large shunts who survive infancy without operation are likely to develop further pulmonary vascular changes probably due largely to the voluminous blood flow through the lungs and the markedly raised pressure. Lynfield, Gasul, Arcilla, and Luan (1961) stressed that when infants with ventricular septal defect develop symptoms in the first year of life, the prognosis without operation is bad due to increasing pulmonary hypertension and pulmonary vascular resistance.

Eighteen of our 45 patients had isolated ven- $\frac{}{c}$ tricular septal defects, and of these only one died $\frac{\bar{\sigma}}{\bar{D}}$ 10 weeks after banding, representing a mortality $\vec{\nabla}$ of $5.5 \%$. This compares favourably with other $\unrhd$ series. Dammann et al. (1961) reported 12 deaths क in $36(33 \%)$, but Craig and Sirak (1963) had a $\vec{\circ}$ mortality as low as $5 \%$ in 18 cases. The 17 who survived pulmonary artery banding have all been $\vec{\omega}$ closely supervised and have shown an improvement in clinical status, with regression of pul- $x$ monary congestion and reduction in the heart size $\underset{\omega}{N}$ in many. The operation for closure of the defect $\rightarrow$ and removal of the pulmonary artery constriction $\omega_{\infty}^{\omega}$ has been successfully performed in two cases, and ${ }^{\circ}$ the other survivors will be submitted to cardiac $\stackrel{5}{5}$ catheterization and angiocardiography at the age $\vec{c}$ of 4 or 5 years, so that the size of the residual shunt may be estimated prior to operative repair.

When additional lesions are present or in patients with complex anomalies, such as single ${ }^{\circ}$ ventricle or common atrio-ventricular canal, the mortality is indeed formidable. Goldblatt et al. (1965) had a mortality of $81 \%$ in 21 infants with

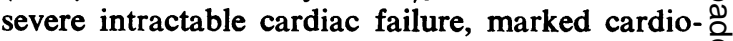
megaly, large left-to-right shunts, and anomalies $\stackrel{\varnothing}{\mathscr{\perp}}$ of the great vessels; whereas in 38 patients with $\overrightarrow{\overrightarrow{0}}$ ventricular septal defect with or without a ductus 3 or atrial septal defect there were 31 survivors (a mortality of $18 \%$ ).

In our series banding of the pulmonary artery was carried out in 27 patients who had either a을 ventricular septal defect with accompanying mal-x formations, or else more complex lesions such as a common atrio-ventricular canal or a single ventricle. There were 15 early deaths in this group, $\frac{O}{2}$ and a further death three months after operation. This formidable mortality $(63 \%)$ is not unexpected 은 in view of the type and multiplicity of the defects $>$ present.

The level of pulmonary vascular resistance in our series appeared to bear no relation to the successful outcome from pulmonary artery band-은 ing. In support of this contention is the illustrative $\omega$ case of the child aged 9 years with a ventricular septal defect who survived despite a pulmonary artery pressure of $160 / 80 \mathrm{~mm}$. $\mathrm{Hg}$ and a P.V.R. of 27 units. Conversely, the solitary death in ${ }^{+}$ group 1 (ventricular septal defect and no other abnormality) occurred in a young child whose $\frac{\vec{\Phi}}{\stackrel{\circ}{*}}$ resistance was 5 units. For technical and other $\stackrel{\odot}{\square}$ considerations the P.V.R. could not be calculated $\stackrel{\mathbb{Q}}{\varrho}$ in all our patients, but from the data available it appeared to be slightly higher in the more complex 0 groups 2 and 3 (range 4 to 20 units) than in those응 
with ventricular septal defect alone ( 3 to 10 units, with the exception of the child aged 9 years alluded to above).

Dammann et al. (1961) reported the results from pulmonary artery banding in 63 patients. Eleven of these were subsequently reoperated on with a view to repair. Four deaths occurred in this group, of whom most had complex abnormalities. Following pulmonary artery banding, sufficient time must elapse to allow regression of the pulmonary vascular changes before further surgery is undertaken. A period of several years is advocated to enable this process to occur.

The initial response to banding is to reduce blood flow through the lungs, thereby relieving pulmonary congestion and cardiac failure. The improvement in the child's condition is often striking, particularly when ventricular septal defect is the sole anomaly. The pulmonary stenosis thus artificially produced prevents further progression of the vascular damage in the lungs, reduces the amount of left-to-right shunting, thereby increasing the systemic flow, and also facilitates further surgical intervention. In the first case in which repeat catheterization was performed (Table II) substantial pulmonary hypertension was still present; despite this the child had shown very gratifying improvement after banding, and subsequent operation for repair was accomplished without incident.

The authors wish to thank Mr. Gray, of the Department of Medical Illustration, Victoria Infirmary, for reproductions of the radiographs and tracings illustrated in the six figures.

\section{REFERENCES}

Auld, P. A. M., Johnson, A. L., Gibbons, J. E., and McGregor, M. (1963). Changes in pulmonary vascular resistance in infants and
children with left-to-right intracardiac shunts. Circulation, 27, 257.

Craig, T. V., and Sirak, H. D. (1963). Pulmonary artery banding. An analysis of 38 cases. J. thorac. cardiovasc. Surg., 45, 599.

Dammann, J. F., McEachen, J. A., Thompson, W. M., Jr., Smith, R., and Muller, W. H., Jr. (1961). The regression of pulmonary vascular disease after the creation of pulmonary stenosis. Ibid., 42, 722.

Friedberg, C. K. (1966). Diseases of the Heart. 3rd ed., p. 1225. Saunders, Philadelphia and London.

Goldblatt, A., Bernhard, W. F., Nadas, A. S., and Gross, R. E. (1965). Pulmonary artery banding. Indications and results in infants and children. Circulation, 32, 172.

Grainger, R. G., Nagle, R. E., Pawidapha, C., Robertson, D. S.. Taylor, D. G., Thornton, J. A., Verel, D., and Zachary, R. B. (1967). Pulmonary artery banding for ventricular septal defect. Brit. Heart J., 29, 289.

Lynfield, J., Gasul, B. M., Arcilla, R., and Luan, L. L. (1961). The natural history of ventricular septal defects in infancy and childhood. Amer. J.'Med., 30, 357.

Morrow, A. G., and Braunwald, N. S. (1961). The surgical treatment of ventricular septal defect in infancy. The technique and results of pulmonary artery constriction. Circulation, 24, 34.

Muller, W. H., Jr., and Dammann, J. F., Jr. (1952). The treatment of certain congenital malformations of the heart by the creation of pulmonic stenosis to reduce pulmonary hypertension and excessive pulmonary blood flow. Surg. Gynec. Obstet., 95, 213.

Nadas, A. S. (1963). Pediatric Cardiology. 2nd ed., pp. 427-428. Saunders, Philadelphia and London.

Ochsner, J. L., Cooley, D. A., McNamara, D. G., and Kline, A. (1962) Surgical treatment of cardiovascular anomalies in 300 infants younger than one year of age. J. thorac. cardiovasc. Surg., 43, 182.

Sloan, H., Mackenzie, J., Morris, J. D., Stern, A., and Sigmann, J. (1962). Open-heart surgery in infancy. Ibid., 44, 459.

Thompson, W. M., Jr., Muller, W. H., Jr., and Dammann, J. F., Jr. (1958). Analysis of clinical results from the surgical creation of pulmonary stenosis in 35 patients with large intracardiac communications. Circulation, 18, 789 . 